\title{
A Study to Assess the Knowledge about Nursing Documentation and Recording Systems of Nursing Care among Staff Nurses
}

\author{
Dr. S. Kala Barathi ${ }^{1 *}$, Mrs. S. Prashanthi ${ }^{2}$
}

${ }^{1}$ Principal, Saveetha College of Nursing, SIMATS, Thandalam, Chennai, Tamil Nadu 602105, India

${ }^{2}$ M.Sc (Nursing) II Year, Saveetha College of Nursing, SIMATS, Thandalam, Chennai, Tamil Nadu 602105, India

DOI: $10.36348 /$ sjnhc.2020.v03i03.001

| Received: 22.02.2020 | Accepted: 01.03.2020 | Published: 21.03.2020

*Corresponding author: Dr. S. Kala Barathi

\section{Abstract}

Nursing documentation is a crucial part of the nursing process as it the essential way of communication within the health care team regarding patient care. Nurses' knowledge about documentation is important as it a legal requirement and main responsibility of nursing staff. Objectives: To assess the nurse's knowledge and recording system nursing documentation among staff nurses and to assess level of knowledge nursing documentation and recording systems of nursing care among staff nurses. Methodology: Quantitative approach with Descriptive design was used for the study. Convenience sampling technique was used to assess level of knowledge regarding system nursing documentation. Results: The study results show that the overall knowledge among 50 Staff nurses $12(24 \%)$ had moderately adequate knowledge, 31(62\%) had adequate knowledge and only $07(14 \%)$ had inadequate knowledge regarding legal and ethical aspects among maternity staff nurses.

Keywords: Nursing Documentation, Recording Systems of Nursing Care and Staff Nurses.

Copyright @ 2020: This is an open-access article distributed under the terms of the Creative Commons Attribution license which permits unrestricted use, distribution, and reproduction in any medium for non-commercial use (NonCommercial, or CC-BY-NC) provided the original author and source are credited.

\section{INTRODUCTION}

Nursing documentation has been one of the most important functions of nurses since the time of Florence Nightingale because it serves multiple and diverse purposes. The intention of nursing documentation is to demonstrate that an organization maintains comprehensive written evidence of its planning, delivery, assessment and evaluation of patient's care [1].

Nursing documents are recorded information regarding patients' problems and interventions that conducted for obviating these problems. These documents are considered as a suitable written communication device. And despite of their basic role in improving and continuance of nursing and medical interventions provided for patients, transferring patients information to other health team members, enhance professional autonomy, critical thinking skills of nurses, development of professional knowledge and nursing education, but the most important role of it is the legal aspect, because the best witness to show health interventions provided for patients is a suitable and correct document [2].
The statistics from developed countries showed that in $74 \%$ of cases the errors of health care providers reported to judicial authorities. Documentation is one of the most important practices in nursing. It sounds that nothing can reflect the total amount of nursing care giving to the patients as documentation does. Therefore, with reliance of the facts previously mentioned and in order to identify nurse's knowledge regarding principles and purposes of nursing documentation, this study was carried out [3].

Documentation is an integral part of nursing and midwifery practice as effective communication among health professionals is vital to the quality of client care. The standard of care rendered by nurses is determined by effective documentation, without which nurses" care is not complete. "Record keeping is an integral part of nursing and midwifery. It is a tool of professional practice and one that should help the care process. It is not separate from this process and it is not an optional extra to be fitted in if circumstances allow" [4].

The documentation of nursing assessment is the recording of the process about how a judgment was made and its related factors, in addition to the result of the judgment. It makes the process of nursing 
assessment visible through what is presented in the documentation content [5].

During nursing assessment, a nurse systematically collects, verifies, analyses and communicates a health care client's information to derive a nursing diagnosis and plan individualized nursing care for the client. Complete and accurate nursing assessment determines the accuracy of the other stages of the nursing process Ehrenberg \& Ehnfors, 2017. A retrospective audit of all nursing notes in patient records was made before and after the educational. Ehrenberg and Ehnfors reported improvements in the contents of the records in the study group with notes on nursing history being doubled. Also, significant increases were noted in the recording of nursing diagnoses, goals and discharges. No corresponding changes were noted in the reference group. Ehrenberg and Ehnfors reported that no record met the requirements of the national regulations on nursing documentation or followed the nursing process thoroughly [6].

Johnson, Jefferies and Langdon [16], in developing the standards for quality nursing documentation, implemented an educational program and initiated audit of a sample of health care records within a clinical setting. Johnson et al., explored the use of an educational intervention to improve nursing documentation of patient care [7].

\section{OBJECTIVES OF THE STUDY}

1. To assess the nurse's knowledge and recording system nursing documentation among staff nurses.

2. To assess level of knowledge nursing documentation and recording systems of nursing care among staff nurses.

\section{METHODS AND MATERIALS}

Descriptive design was adopted by the investigator to assess the nurse's knowledge and recording system nursing documentation among staff nurses. The study was conducted at Saveetha Medical College Hospital. The samples who met the inclusion criteria were selected by using convenience sampling technique. Nurses working in inpatient wards and outpatient departments; nurses having work status as a professional nurse at least for 6 months and those who were voluntary to participate were included in the study. Fifty samples were selected for the study. Data was collected using a structured self-administered questionnaire to collect data regarding demographic variables and to assess the knowledge regarding nursing documentation. The project has been approved by the ethics committee of the institution. Informed consent was obtained from the participants before initiating the study

\section{RESULTS AND DISCUSSION}

The present study characteristics show that 50 respondents participated in this study. From 50 nurses who participated in this study, $33(65 \%)$ were females and $17(35 \%)$ were males. Two hundred eight $(65 \%)$ fall within the ranges of 25-34 years age group. Most of the respondents were holding diploma degree $44(88 \%)$. $24(48 \%)$ of them were senior nurse professionals while $23(46 \%)$ were junior nurse professionals and $3(6 \%)$ were junior clinical nurses. One third of the participants were worked as a nurse for 2-5 years when 16 (33\%) and $15(31 \%)$ of them worked for more than 5 years and less than 2 years respectively.

Frequency and percentage level of knowledge nursing documentation and recording systems of nursing care among staff nurses

\begin{tabular}{|l|l|l|}
\hline LEVE OF KNOWLEDGE & No. & $\%$ \\
\hline Inadequate & 07 & 14.0 \\
\hline Moderately adequate & 12 & 24.0 \\
\hline Adequate & 31 & 62.0 \\
\hline
\end{tabular}

The present study result shows that $12(24 \%)$ had moderately adequate knowledge, 31(62\%) had adequate knowledge and only $07(14 \%)$ had inadequate knowledge regarding legal and ethical aspects among maternity staff nurses.

The result of this study shows that practice nursing care documentation was inadequate $(47.8 \%)$ among nurses similar to Nigeria where both the documentation practice and knowledge were found to be insufficient. This finding is higher from Indonesia $33.3 \%$ and University of Gondar hospital (37.4\%) This discrepancy might be due to difference in the study period since there might be information difference with time gap because the studies were done before 2 years and after technology had faster growth like smart care introduced in most hospitals of Ethiopia. The other reason could be nurses educational development variation across the countries. Most $(52.2 \%)$ of the study participants in this study revealed poor nursing documentation practice which coincides with a study done in Felege Hiwot referral hospital $(87.5 \%)$ where medication administration errors were due to nursing documentation error. This finding is lower than a finding from South Africa $68.3 \%$ and Nigeria $70 \%$. This might be due to insufficient knowledge as indicated in those studies favourability of the working environment and organizational structure [8-15]. 


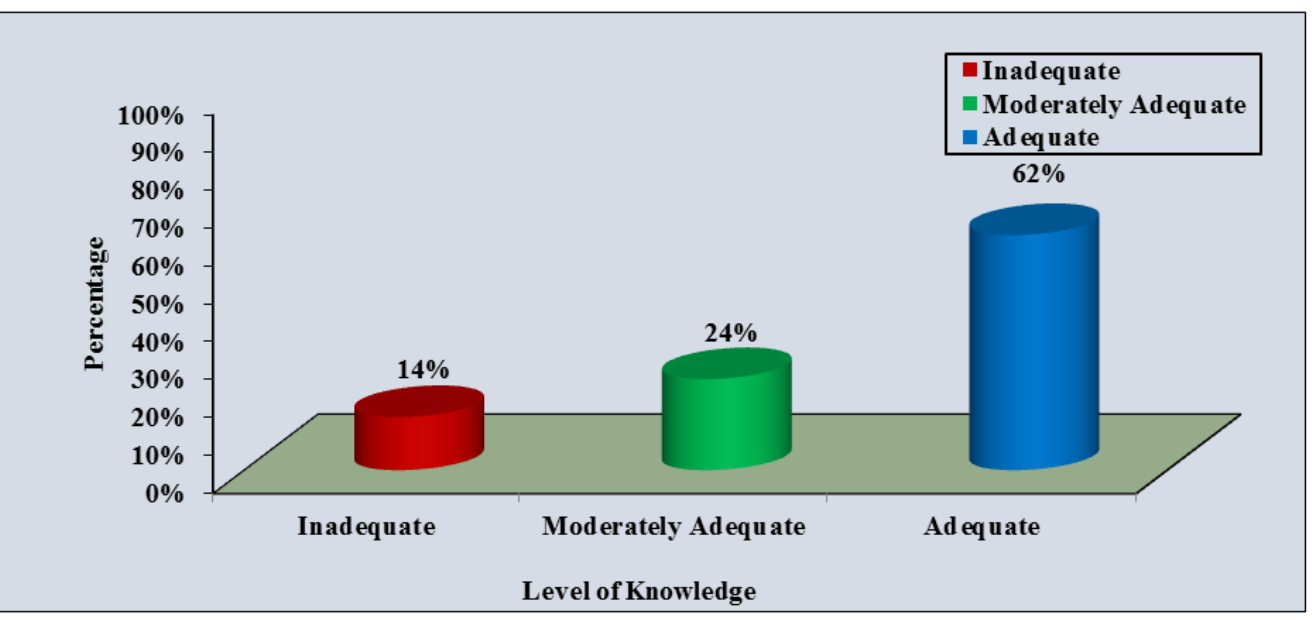

Percentage distribution of level of knowledge nursing documentation and recording systems of nursing care among staff nurses

\section{CONCLUSION}

Nursing care documentation practice was poor among nurses. Inadequacy of documenting sheets, lack of time and familiarity with operational standard of nursing documentation were factors associated with nursing care documentation practice. The following recommendation should forward to the healthcare facilities to Provide a training program to enhance the knowledge of nurses and to familiarize them with institutional policy regarding documentation and provide adequate documentation materials.

\section{REFERENCE}

1. Urquhart, C., Currell, R., Grant, M. J., \& Hardiker, N. R. (2009). Nursing record systems: effects on nursing practice and healthcare outcomes. Cochrane database of systematic reviews, (1):1-66.

2. Daskein, R., Moyle, W., \& Creedy, D. (2009). Aged- care nurses' knowledge of nursing documentation: an Australian perspective. Journal of Clinical Nursing, 18(14), 2087-2095.

3. College of Registered Nurses of Nova Scotia. Documentation guidelines for registered nurses. 2012; http://www.crnns.ca.

4. Federal Democratic Republic of Ethiopia. (2005). The Criminal Code of the Federal Democratic Republic of Ethiopia. Proclamation No. 414/2004.

5. Ente, C., Oyewumi, A., \& Mpora, O. B. (2010). Healthcare professionals' understanding and awareness of patient safety and quality of care in Africa: a survey study. International Journal of Risk \& Safety in Medicine, 22(2), 103-110.

6. Collins, S. A., Cato, K., Albers, D., Scott, K., Stetson, P. D., Bakken, S., \& Vawdrey, D. K. (2013). Relationship between nursing documentation and patients' mortality. American Journal of Critical Care, 22(4), 306-313.

7. Lindo, J., Stennett, R., Stephenson- Wilson, K., Barrett, K. A., Bunnaman, D., Anderson- Johnson, P., ... \& Wint, Y. (2016). An audit of nursing documentation at three public hospitals in
Jamaica. Journal of Nursing Scholarship, 48(5), 499-507.

8. Broderick, M. C., \& Coffey, A. (2013). Personcentred care in nursing documentation. International journal of older people nursing, 8(4), 309-318.

9. Jasemi, M., Zamanzadeh, V., Rahmani, A., Mohajjel, A., \& Alsadathoseini, F. (2012). Knowledge and practice of Tabriz teaching hospitals' nurses regarding nursing documentation. Thrita, 2(2), 133-138.

10. Gomes, D. C., Cubas, M. R., Pleis, L. E., Shmeil, M. A. H., \& Peluci, A. P. V. D. (2016). Terms used by nurses in the documentation of patient progress. Revista gaucha de enfermagem, 37(1):e53927.

11. Considine, J., Trotter, C., \& Currey, J. (2016). Nurses' documentation of physiological observations in three acute care settings. Journal of clinical nursing, 25(1-2), 134-143.

12. Johnson, B. B. (2011). Nursing documentation as a communication tool:(a case study from Ghana) (Master's thesis, Universitetet i Tromsø).

13. Sum, M. T., \& Chebor, M. A. (2013). Documentation: historical perspectives, purposes, benefits and challenges as faced by nurses. Int $J$ Hum Soc Sci, 3(16), 236-240.

14. Kebede, M., Endris, Y., \& Zegeye, D. T. (2017). Nursing care documentation practice: The unfinished task of nursing care in the University of Gondar Hospital. Informatics for Health and Social Care, 42(3), 290-302.

15. Taiye, B. H. (2015). Knowledge and practice of documentation among nurses in Ahmadu Bello University Teaching Hospital (Abuth) Zaria, Kaduna State. Journal of Nursing and Health Science, 4(6), 1-6.

16. Jefferies, D., Johnson, M., \& Langdon, R. (2015). Rekindling the role of nurses in patients' oral nutrition. International journal of nursing practice, 21(3), 286-296. 